\title{
Survey on Environmental Monitoring Requirements of European Ports
}

\author{
R.M. Darbra ${ }^{* 1}$, N. Pittam ${ }^{2}$,K.A. Royston ${ }^{1}$, J. P. Darbra ${ }^{1}$, Journee, H. ${ }^{1}$ \\ ${ }^{1}$ EcoPorts Foundation, De Ruijterkade 7, 1013AA Amsterdam \\ ${ }^{2}$ ABP Marine Environmental Research Ltd (ABPmer), Suite B Waterside House, \\ Town Quay, Southampton, S014 2AQ, UK
}

\begin{abstract}
A group of 26 European ports were interviewed to understand their requirements for environmental information and to establish how widespread the use of earth observation (EO) data was amongst them. Aspects covered by the research included port profile characterisation, environmental management activities, environmental needs and current monitoring practices. The study reflected the diversity amongst European ports and their environmental performances. Most of the ports were publicly owned and located in estuaries and rivers. General cargo was the most popular commodity handled. Practically all the ports had an environmental policy in place and half of them had been accredited by an external body. The main environmental parameters that ports required to be monitored were marine related issues (currents, waves, and tide), water quality, meteorological parameters, turbidity and sediment processes. The principal driver for monitoring was maintaining key port operations, followed by legislation, and local responsibilities. Ports in general collected their own data in situ and only one third had used remotely sensed data
\end{abstract}

\footnotetext{
* Corresponding author: Tel. +34 670714616; fax: +34 93 2045904; E-mail address: rmdarbra@yahoo.es
} 
(data from Earth Observation satellites or from airplane mounted sensors) for environmental purposes. Half of them used computer modelling. This study was conducted within the framework of the European funded port environmental information collector project (PEARL).

Keywords: port, environmental monitoring, marine data management, remotely sensed, in situ data, coastal zone

\section{Introduction}

One of the main challenges identified by the European Sea Ports Organisation (ESPO) in its environmental code (ESPO, 2003) was the sustainable development of sea ports. The port may be the cause of environmental impacts in its surrounding area (inside and outside). It is the receptor as well as the emitter of impacts. Environmental issues are of strategic relevance for European ports. The environmental impacts caused by port related activities should be reduced (Trozzi and Vaccaro, 2000). The first step is to properly manage environmental issues which requires continuous environmental monitoring.

European legislation is the main driver of the need for environmental management tools. Remote and continuous monitoring is a key aspect of improving the understanding of port environmental conditions. It also aids management of risk situations (e.g. oil spills, accidents) that might affect the port.

Monitoring is an essential part of the implementation of any environmental management system (EMS). The ISO 14001 (International Standard Organization, 2004) and Ecomanagement and Audit Scheme-EMAS (European Parliament and the Council of the 
European Union, 2001) international standards and the PERS standard (Port Environmental Review System) (Journee and Wooldridge, 2005) require the identification and monitoring of environmental aspects. In addition, monitoring is necessary to ensure port managers are better prepared to face any eventualities that may occur in a port, including emergency situations.

In a survey carried out by ESPO (European Sea Ports Organization) in 2004, the top ten port environmental issues for European ports were identified (see Table 1, left column). These are the key environmental issues that ports highlight as the most important to be managed. In order to do so there is a clear need to further improve environmental data monitoring techniques. To be able to manage the port environment, data must be collected and used by those involved and responsible for environmental management. In situ data (collected from sensors and instrumentation at the port) are the most common type of measurements taken. They are relatively easy to take on both the port land and local waters. These measurements can only provide local, single position coverage which may be of varying frequency and expensive to maintain. To support in situ data collection, remotely sensed data is also sometimes collected by airplane and satellite mounted sensors (wider area coverage). This has the additional benefits of ease and speed of data acquisition, often at sensitive or difficult to access locations.

A number of previous European Community (EC) and European Space Agency (ESA) studies (e.g. Starlab, 2005a and 2005b) have highlighted that ports under utilise remotely sensed 'space' data (from instruments mounted on satellites) and that these instruments could provide valuable environmental information. 
As a result of this finding, an EC project called PEARL (port environmental information collector) was developed (2006-2008). Its aim was to research and improve the understanding of the environmental monitoring needs of European ports; and support development of a port Environmental Management System (EMS) enabling optimal exploitation of space and in situ data products.

As part of the project a set of 26 European ports were interviewed. The main results of this research are presented in this paper. The research outcomes can provide ports with a better understanding of their monitoring requirements and other ports experiences.

\section{The PEARL project}

PEARL is an EC funded project within the Sixth Framework Programme (http://www.PEARL-project.eu). It commenced in January 2006 and will conclude in December 2008.

PEARL seeks to bring together current working practices and other options for data measurement within ports, to establish a port environmental information system platform capable of optimal exploitation of remotely sensed data, in situ data products and computer models.

The main aim of the project is to develop and trial the PEARL 'Platform'. This is a working example of the data fusion concept. It will allow access to and interrogation of 
data by port environmental managers and data users. Both land based and marine environmental data types are investigated.

A large number of data systems are already in place to gather relevant geo-information data, which are traditionally meteorological, water quality, oceanographic and pollution related. The systems presently used are predominantly in situ sensors that are used to gather specific data within or surrounding the port area.

Improving information flow by increasing the number of in-situ sensors deployed is a costly investment strategy. Earth Observation (EO) data could provide valuable information (e.g. weather forecasts, wave movement, ships position) in coastal areas which are applicable for port requirements.

For the first time, PEARL aims to provide a port focussed data management platform enabling user-friendly access to all data types. In situ, remotely sensed airborne and satellite data and model data will be combined in the platform. PEARL also aims to educate the user community on the information content available from space and in-situ instruments and its current limitations.

The results presented in this paper are from the PEARL work package 2, led by ABP Marine Environmental Research Ltd (ABPmer) with the EcoPorts Foundation (EcoPorts). Its main objective is to provide an overall understanding of the present day requirements for marine environmental data. 
The findings on the environmental data uses and requirements will be used in the subsequent PEARL work packages. Existing remotely sensed data products and services, models and in situ sensors will then also be reviewed. Those most relevant to port authorities will be selected to use as a basis for the PEARL platform development and subsequent validation pilots.

\section{Methodology}

\section{$\underline{3.1 \text { Literature review }}$}

The first environmental management initiatives in port areas began with the European Sea Ports Organisation (ESPO) as a response to the need of European ports to be represented in Europe. Founded in 1993 ESPO published an environmental code of practice for EU ports (ESPO, 1994 and 2003) and produced a number of environmental surveys (ECOinformation, 1999; ESPO, 2005) among many other environmental initiatives.

In 1997, the ECO-information project (Eco-information, 1999) was launched. It aimed to improve environmental conditions in port areas and support the development of a level playing field between European ports and their environmental performance. In 2000 the ECOPORT project (Autoridad Portuaria de Valencia, 2001; Peris-Mora et al., 2005) made the first attempt to implement an environmental management system in ports. Later, in 2002, the ECOPORTS project (Darbra et al., 2004) continued the work started by these previous projects. It also expanded the growth of environmental awareness through European ports. 
In other parts of the globe, there were also initiatives concerning environmental impacts in ports. For example in 1998 the American Association of Port Authorities (AAPA) developed a manual to assist ports in the effective management of environmental problems (AAPA, 1998).

In 2004 the EC project 'Local Harbour Authorities Earth Observation (EO) Response for Ocean Monitoring (LHEON) project was completed. This focussed more on Earth Observation aspects. LHEON (Starlab 2005a and Starlab 2005b) investigated how EO data could respond to local harbours' monitoring needs. Other projects focussed on the coastal and marine environment and remote sensing information were also reviewed. Their main objectives are summarised in Table 2.

\subsection{Questionnaire design and interviews}

Once the initial bibliographic and Internet research was completed, a questionnaire was designed to improve the understanding of the ports environmental needs and requirements.

The ESPO Survey (ESPO, 2005) and the Lloyd's Register accredited Ports Environmental Review System (PERS) Certificate from EcoPorts (Journee and Wooldridge, 2005) were very useful when designing the questionnaire. The port profile information collected from 129 ports in the ESPO survey, and the information from PERS ports, had already summarised much of the port profile information required for PEARL.

The questionnaire consisted of six different parts: 
1. Port Sector Profile: comprising a set of questions about the main port characteristics (figure 1).

2. Port Organogram: the port was asked to provide the organogram of the port showing how environmental responsibilities are managed.

3. Information tables about space, airborne and in-situ data products. This information was very helpful for the ports when completing the questionnaire interviews.

4. Needs Identification Questionnaire: aimed at identifying the needs of ports concerning environmental monitoring.

5. Products Specification Questionnaire: aimed at identifying the characteristics of the final products (platform).

6. Port Environmental Information Requirements Questionnaire: asked questions on environmental management, current data use and practices and awareness of EO products (see figure 2).

The questionnaire was sent to the port representatives in advance. This approach enabled them to fill in data such as the port profile or port organogram prior to the interview. This allowed extra time to focus on environmental needs and product specifications during the interview. Interview preparation included collection of general port information from public domain sources including the ports websites.

Each interview was conducted by two PEARL project members from ABPmer or EcoPorts and usually involved two port representatives. This arrangement was intended to ensure representation from both environmental management and technical data management 
personnel. This enabled questions to be answered fully from a broad knowledge base. Outstanding questions were followed up within a week of the interview.

\subsection{Ports Contacted}

A sample of ports across Europe was selected to conduct a representative survey. The selected ports covered a broad geographical scope (including estuarine, riverine and inland), and a range of sizes. To ensure that the research was representative, a list of ESPO ports was obtained and used to compile a list of European Union member state ports. At least one port within each of the 21 non-land-locked EU member state countries were contacted and invited to participate in PEARL.

Use was made of existing port contacts (ABPmer and EcoPorts enjoy strong connections with a number of European ports) to improve the chances of port co-operation and high quality responses and information. A total of 26 ports from 12 member states agreed to participate and provided information to PEARL.

There were a number of reasons why the other ports contacted were unable to participate. They included time pressures; holiday commitments; difficulty in obtaining approval to participate and no interest. Of the ports contacted 24 were not able to participate. PEARL, however, considered the information provided by the other 26 EU ports to be very useful for the project and also deserved to be made available to the public. There has been little research on this subject. For this reason these first results are important as a base against which to measure future trends. 


\section{Results and Discussion}

In this section, results from three different aspects of the interviewed ports are presented: port profile, environmental management and environmental monitoring requirements/practices.

\subsection{Profile of Ports}

- Most of the ports interviewed were publicly owned (64\%). This included state ports, municipalities and regional ports. The remaining ports were privately owned (24\%) or were trust ports ${ }^{\dagger}(12 \%)$.

- The most common geographic locations were estuaries (28\%) and rivers (20\%) followed by marine inlet (16\%) and engineered coast (16\%) (see figure 1 for the geographic location).

- Port areas (land and navigable water) varied significantly reflecting the diverse range of ports interviewed. Concerning the port landside, most of the ports interviewed covered hinterland areas of between 500 and 1000 hectares (37\%), followed by 100 to 500 hectares (25\%). With reference to the seaward side, most have either less than 500 hectares or 1000 to 2500 hectares, each accounting for $24 \%$ of the cases.

\footnotetext{
${ }^{\dagger}$ Trust ports are independent statutory bodies, each governed by its own, unique, local legislation and controlled by an independent board. There are no shareholders or owners. Any profit is invested back into the port for the benefit of the stakeholders of the trust. The stakeholders are all those using the port, employees of both the port and its users and all those individuals, organisations and groups having an interest in the operation of the port. This port category is mainly used in UK.
} 
- The majority of port jurisdiction limits onshore (on land) were between 0.5 and 2 kilometres whereas the most common range of limits offshore were between 5 and 10 $\mathrm{km}$.

- Twenty principal activities were recorded with 'general cargo' being the most common commodity handled (84\%) followed by 'dry bulks’ (76\%), 'liquid bulks (non-oil)' (64\%), 'fresh produce and perishables' (60\%), with 'containers' and 'oil and petroleum' both being handled by 56\% of the ports interviewed (Figure 3).

- Regarding the port business size (based on the most recent annual statistics available):

- The most common total annual tonnage was between 5 and 15 million (36\%), followed by less than 5 million tonnes per year (20\%) based on 25 responses.

- The majority of ports handled less than 250 thousand containers (TEU ${ }^{\ddagger}$ s) annually

- Half of the ports carried less than 1 million passengers annually

- $\quad$ Turnovers were very varied with an average of 68 million euros annually

\subsection{Environmental Management Results}

The Environmental Management section of the interview was included to gain an understanding of the importance placed on environmental issues within the ports.

\footnotetext{
‡ Twenty-Foot Equivalent Units
} 
Questions were asked about different elements of the environmental management system. The main results are presented below:

- $93 \%$ of the ports interviewed had drawn up an environmental policy which included statements regarding compliance with legislation, commitment to the prevention of pollution, continuous improvement and commitment to sustainable development.

- The Environmental representatives were based within a variety of departments including engineering, marine, harbour masters, industrial safety, conservancy, maintenance, marketing, health and safety and corporate services.

- The number of staff directly employed within Environmental Management varied greatly between those ports interviewed, ranging from 0 to 10 people. The average was 2.7 staff.

- In $64 \%$ of the surveyed ports there was a specific environmental budget. In $24 \%$ of the cases, the environmental monitoring was carried out through indirect and more general budgets and $12 \%$ had no budget for environmental monitoring.

- Of the ports interviewed, $64 \%$ had been accredited by a recognised organisation (Figure 4). The most popular group was PERS certification, followed by ISO 14001. Having an accreditation was seen as a positive differentiator. 


\subsection{Environmental monitoring requirements}

\subsubsection{Environmental Needs Identification}

Figure 5 shows the broad range of different parameters ports needed to monitor for their normal operation. There is much difference in their nature including environmental aspects, geophysical parameters, marine issues, etc. The main group belonged to "Others" (26.5\%). This represented many different parameters (with very low percentages) in which ports were interested. Of those, the most important were habitat monitoring and heat loss from buildings (1.5\% each). A ranking of the top ten environmental monitoring needs (after “Others”) is presented below:

1. Marine related issues (13.3\%). This parameter included information on currents, waves and tides. Monitoring these aspects was very important to ensure safe shipping and navigation, prediction of dispersion of pollution (e.g. oil spills), identification of sources of pollution, determination of the direction of port expansion and assuring pilotage activities.

2. Water quality (11.7\%). This aspect involved the monitoring of different parameters such as salinity, water temperature, nutrient levels and dissolved oxygen. Legal requirements, protection of the coastal environment and image of the port (e.g. rubbish in the port) were the main drivers for this monitoring. Measuring water temperature allowed identification of thermal plumes and their sources, assessment of seasonal changes and detection of nonnative algae. The monitoring of the salinity was useful to study the exchanges of sea water and fresh water in the port area as well as to assess the depth of the port (sea water is more dense than fresh water and it sinks to the bottom). 
3. Meteorological parameters (8.7\%). Most of the ports were already obtaining data on atmospheric pressure, humidity, rainfall and temperature from meteorological stations located throughout the port area. Wind speed/direction data for the port and surrounding areas were also included here. This information was essential to ensure safe navigation and to minimize environmental impact (i.e. identification of source and fate) especially when an incident had occurred (e.g. dust dispersion, fire, gas cloud, air pollution, oil spillage).

4. Turbidity and sediment processes (7.7\%). These aspects were normally related to port dredging activities and expansion works. When these operations took place the turbidity of the water increased, with more suspended solids and this could affect fauna and flora, and obviously water quality. Therefore monitoring the impact of these activities was extremely important. The characterisation of the sediments was another aspect that sea ports, and especially inland ports, highlighted as a very important issue. Sediments needed to be analysed before their final fate was decided (treatment or containment).

5. Oil spill (6.6\%). Monitoring oil spillages not only minimised the environmental risk but also helped to identify polluters and provide evidence to make them pay for the cleaning costs. Ports would have liked to have information on this parameter constantly, including at night when visual inspection was not possible. The subsequent oil plume dispersion was related to the currents, sea state and local wind conditions. Therefore monitoring wind was very important for ports since it could be used in computer models to predict the likely dispersion. 
6. Air quality (6.1\%). Ports needed to have data mainly on dust, nitrogen oxide, sulphur oxide, carbon dioxide and other chemical pollutants from oil terminals (e.g. hydrocarbons). The production of chemical pollutants in the ports interviewed came mainly from the oil terminals and chemical plants. The odour released by these substances was the source of many complaints from local communities.

7. Ballast water monitoring (4.1\%). It allowed identifying those ships that were releasing their ballast water to the port (affecting water quality) and as a consequence the introduction of alien species into the ecosystem with its resultant risks. The International Maritime Organization (IMO) guidelines on ballast water will enter into force in 2012. It was considered important to start monitoring this parameter as soon as possible.

8. Noise monitoring (4.1\%). The main reason for monitoring this parameter was the effects of noise upon the population and activities located close to the port area, as well as on the port employees. Identifying the sources of disturbance was one of the main needs of those EU ports close to cities.

9. Dust dispersion (4.1\%). Ports were interested in monitoring two different sizes of particles of coarse dust, 2.5 and 10 micrometers in diameter. This is mainly due to its effects on the surrounding population. The origin of dust was mainly related to solid bulk handling, storage and transport but also to some industries (e.g. coal factories) and ferries. According to the interviewed ports, dust monitoring should be conducted not only in the port area but also in the surrounding areas. This would help to identify the real source (port or non port activities). 
10. Soil quality (3.1\%). In the past, historical contamination of port land had existed and it was very difficult to recycle the soil. For this reason, the participant ports were now checking the soil quality on a regular basis to ensure that they could rent out clean spaces. Ground water quality was also included in this category as it may be affected by soil pollution.

A comparison has been made between these top ten environmental needs and the results of the ESPO survey of 2004 (see Table 1). Although the approach to each survey is not exactly the same, several issues are present in both rankings. The ESPO survey was focussed on identifying the environmental issues for ports. The PEARL survey aimed at a better understanding of the environmental data needs of ports. Even if the categories are not exactly the same, issues such as 'turbidity and sediments process' are clearly related with 'dredging and dredging disposal', or 'oil spills' with 'bunkering'.

Dredging and dredging disposal occupied the second and third position in 2004 and now turbidity is fourth in the ranking. Dust and noise are also present in both rankings but they have dropped slightly. Air quality is in the same position. Bunkering was in seventh position but now the control of oil spills is in fifth position. There may have been an increase in the awareness of this aspect. Aspects such as marine related issues (currents, tides and waves) and meteorological parameters occupy first positions. Their monitoring is essential to ensure safe navigation.

\subsubsection{Present Day Monitoring Practices}


This section looks at present-day port environmental data usage and how and why data on the environmental parameters presented in subsection (4.3.1) are obtained and the working practices associated with them. To obtain this information a number of questions within the interview were targeted to investigate the drivers associated with the need for, and methods used to gather, data (figure 2).

The primary current driver for monitoring, according to the interviewed ports, was maintaining the key port operations relating to ship navigation and cargo handling. This was followed by legislative requirements such as:

- International legislation (e.g. MARPOL 73/78, London Convention 1972);

- European Directives (e.g. Water Frame Directive, Habitats Directive) ;

- National legislation (e.g. Environmental Protection act (NL), Health, Safety and the Environment regulations (UK));

Other reasons offered by ports were local responsibilities, such as complaints from third parties, surrounding population and also the port's image.

The port practices for obtaining data varied according to the size and extent of the port. Some who had the capability were expected to gather their own data whilst others relied on data purchase or third parties to provide the necessary information. Generally it was observed that ports with higher tonnage and a more extensive port area had more resources to carry out their own monitoring. Figure 6 shows a bar graph of the current port practices for obtaining data. It also indicates that ports in general collect their data in situ to suit their own requirements. Third party data was sourced equally from consultants or other data providers (on media such as CD-ROM). The total exceeds 26 as some ports were gathering data from two sources. 
A number of methods were used by ports collecting their own data. This ranged from single point sensors providing occasional data readings, to real-time monitoring with data automatically transmitted to an office. The technology used was dependent on the need and appropriate resources.

The most common sources for third party data were:

a. National institutions (Ministries of Environmental Affairs, Ports Associations, National Institutes for Coastal Affairs, National Institutes for Inland Waters);

b. Regional institutions (Environmental Regional Agencies, Institutes of Environmental Management);

c. Environmental accredited firms;

d. Subcontracted companies (private companies carrying out monitoring on specific environmental issues); and

e. Universities.

Other interesting results relating to monitoring practices are summarised below:

- $40 \%$ of the ports interviewed experienced gaps in their data collection (e.g. equipment failure), which could present difficulties in maintaining their routine operational activities. 
- $28 \%$ of the ports stated they had used EO data in some way, with reference mainly to weather forecasts (precipitation), wave measurement and shipping movements.

- $50 \%$ of the ports interviewed used modelling to assist their environmental monitoring. The types used vary including predictive tools such as morphological change analysis, noise, hydrodynamic, air quality monitoring and vessel handling.

- $76 \%$ of the ports questioned had an occasional need to collect data mainly for dredging or dredging related projects (maintenance campaigns or new developments). On the port landside, air quality and noise levels also required occasional monitoring in the event of poor air quality or high noise levels respectively. Complaints from local residents or port based workers could also trigger additional monitoring.

- Incident and emergency monitoring was also carried out on an occasional basis. Examples of this include data collected in response to oil or other chemical spills, their dispersion and possible associated fires.

- An estimation was attempted of the cost and benefits of monitoring. However, it was very difficult for many ports to provide an exact figure (e.g. costs covered by various departmental budgets).

\section{Conclusions and Future Actions}


The information presented in this paper gives an insight into the environmental monitoring requirements of European ports. The assistance of 50 ports from all over Europe was sought, and 26 agreed to participate. From the quantitative and qualitative analysis of the interview responses the general conclusions that may be drawn are:

$>$ Most of the ports interviewed were publicly owned, located in estuaries or rivers, handled "general cargo" and had a defined environmental management structure.

Marine related issues (currents, tides and waves) were the most important parameters to be monitored. This information was very important to ensure safe shipping and navigation. The monitoring parameters required for this were water quality, meteorological aspects, turbidity and sediment processes.

Maintaining the key port operations was the main driver for most ports, followed by legislative requirements and local responsibilities.

Port practices to obtain data varied according to the size and extent of the port. In general ports collected their own data in situ. Computer modelling was also used as a source of environmental data.

The EO data was not routinely used by ports and their data suppliers. This suggests that there were market blockages preventing its use (e.g. spatial resolution, cost, knowledge of available data types, access to data, etc.).

With these results, the PEARL project plans to continue its work by combining the data (in situ, airborne, modelling and satellite), developing the platform and validating its use with a set of trial ports. 
The final step will be disseminating the results and promoting the tool to European ports. It is hoped that PEARL can provide ports with a platform for managing all their environmental data and supporting sustainable environmental management.

\section{Acknowledgements}

The authors would like to acknowledge:

- PEARL project partners for their contribution and assistance:

Atos Origin, Starlab Barcelona, S.L, Ifremer, BOOST Technologies, Polish Academy of Science-Space Research Center, ABPmer, EcoPorts Foundation.

- European Commission for the funding received (PEARL project no. 12290). PEARL is a specific Targeted Research Project funded by the European Commission under the 6th Framework Programme in the Aeronautics and Space activity area.

- $\quad$ All of the ports that were interviewed.

\section{References}

AAPA (1998). Environmental Management Handbook. American Association of Port Authorities. Available at: http://www.aapa-ports.org/search/

Autoridad Portuaria de Valencia, 2001. Guía para la implantación de sistemas de gestión medioambiental en instalaciones portuarias. APV, Valencia. 
Cotton, D., Le Bras, J-Y., Johannessen, J., Maiques, A., Perivdiotis, L., Aloisi, R., 2006.

ROSES: Real-time Ocean Services for Environment and Security tracks oil pollution and toxic algal blooms. On-line: http://www.aviso.oceanobs.com/html/swt/yp/roses_uk.html Last Access 26th of June 2007

Darbra, R.M.; Ronza, A.; Casal, J.; Stojanovic, T.; Wooldridge, C. (2004). “A New Methodology to Assess Environmental Management in Sea Ports”. Marine Pollution Bulletin, 48 (5-6): 420-428.

Desaubies, Y., 2003. The MERSEA project: Development of a European system for operational monitoring and forecasting of the ocean on global and regional scales. Online:- http://earth.esa.int/cgi-bin/confalt15y.pl?abstract=928 Last Access 26th of June 2007

ECO-information 1999. ECO-information in European Ports. Final Report, ESPO, Brussels.

ESA, 2006. GlobColour Project, European Node for Global Ocean Colour. On-line: http://www.globcolour.info/ Last Access 26th of June 2007

ESPO, 1994. Environmental Code of Practice. ESPO, Brussels.

ESPO, 2003. Environmental Code of Practice. ESPO, Brussels. On-line http://www.espo.be/downloads/archive/85817e87-5a24-4c43-b570-146cb7f36b68.pdf 
Last Access 26th of June 2007

ESPO, 2005. ESPO Environmental Survey 2004 - Review of European Performance in Port Environmental Management, European Sea Ports Organisation, April 2005. http://www.espo.be/downloads/archive/36f31a9e-e902-40c1-85ef-a9826324f6d5.pdf Last Access 26th of June 2007

European Parliament and the Council of the European Union, 2001. Regulation (EC) no. 761/2001 of the European Parliament and of the Council of 19 March 2001 allowing voluntary participation by organisations in a community eco-management and audit scheme (EMAS). Official Journal of the European Communities L 114, 1-29. On-line http://eur-lex.europa.eu/LexUriServ/site/en/oj/2001/1_114/l_11420010424en00010029.pdf Last Access 26th of June 2007

International Standard Organization, 2004. EN ISO 14001. Environmental Management Systems - Specification with Guidance for Use. CEN, Brussels.

Jolly, G.W., Mangin, A., Cauneau, F., Calatuyud, M., Barale, V., Snaith, H.M., Rud, O., Ishii, M., Gade, M., Redondon, J.M., Platinov, A., 1998. Clean Seas, Final Report, Onlilne: http://www.satobsys.co.uk/CSeas/report.html Last Access 26th of June 2007

Journee, H. and Wooldridge, CF. A New Standard for Port Environmental Management — A European Port Sector Initiative. Tropical Coasts, December 2005.

Mahony, C.O., Cummins, V., Dwyer, N., Connolly, N., 2003. Final User Requirements Document. On-line:http://marsais.ucc.ie/Marsais\%20brochure/Final\%20URD\%20\%20.pdf 
Last Access 26th of June 2007

Medspiration, 2006. The Medspiration Project - An Introduction. On-line:

http://www.medspiration.org/project/ Last Access 26th of June 2007

MTS, 2002. Information System for Marine Aquatic Resource Quality (IMARQ), User Requirement Definition, October 2002.

MTS, 2005. Information System for Marine Aquatic Resource Quality (IMARQ), Final Report, June 2005.

Peris-Mora, E., Orejas, J. M. D., Subirats, A., Ibáñez, S., \& Alvarez, P., 2005. Development of a system of indicators for sustainable port management. Marine Pollution Bulletin, 50(12), 1649-1660.

QinetiQ, 2005. GMES OCEANIDES: Report on data issues and assessment of capacity for long-term routine oil spill monitoring, February 2005. On-line: http://oceanides.jrc.it/Deliverables/D10_v2.pdf Last Access 26th of June 2007

Sandven. S., Hamre, T., Hackett, B., Sorensen, K., Robbe, N., Ziemer, F., Bogdanov, A., Gemelli, G., Nirchio, F., Cauneau, F., Tuama, E.O., Groom, S., Parthiot, F., Trivero, P., Populus, J., Folkestad, A., Pettersson, L.H., Cysewski, M., Lewis, K., Le Roux, J.F., Hokedal, J., Karud, J., Biamino, W., DISMAR, 2005. Data Integration System for Marine Pollution and Water Quality, NERSC Technical Report No.266, Deliverable D11, 
DISMAR Final Report, DISMAR Report No.19, 20 December 2005, Version 1.0, Public. On-line:- http://cmrc.ucc.ie/publications/reports/D11_DISMAR_Final_Report.pdf Last Access 26th of June 2007

Starlab, 2005a. Local Harbour Authorities EO Response for Ocean Monitoring, LHEON Final Report, Phase 1 and 2 main findings.

Starlab, 2005b. Local Harbour Authorities EO Response for Ocean Monitoring (ESA Reference AO/1-4365/03/I-LG)WP2000 Report: D2.2 Analysis Report - Impact of Market Drivers on Demand and Supply of EO Based Geo-Information, May 2004.

Starlab, 2006. MarCoast, MarCoast publications. On-line: www.gmes-marcoast.com. Last Access 26th of June 2007

Trozzi, C. and Vaccaro, R., 2000. “Environmental Impact of Port Activities”, in Brebbia, C.A. and Olivella, J. (eds.), Maritime Engineering and Ports II, WIT Press, Southampton, pp.151-161. 